\title{
Improving Occupational and Industrial Safety Management System at Coal Mining Enterprises
}

\author{
Svetlana Smagina, ${ }^{1, *}$, Oksana Kadnikova ${ }^{2}$, Ksenia Demidenko², Galina Chistyakova $^{2}$, and \\ Anastasia Rolgayzer ${ }^{2}$ \\ ${ }^{1}$ Kemerovo State University, Department of Psychology, 650000 Krasnaya St. 6, Kemerovo, Russia \\ 2 Plekhanov Russian University of Economics, Kemerovo Institute (branch), Department of \\ Humanities, 650992 Kemerovo, Kuznetskiy Av. 39, Russia
}

\begin{abstract}
The article highlights the problem of mine workers occupational safety. The foreign and domestic experience of the field is analyzed. Some areas, activities and methods that meet modern requirements for ensuring occupational safety and production development, which are aimed at improving the quality of occupational safety management system, are described. The possibilities of their use in industrial safety of Kuzbass coal mining enterprises are considered. The proposed methods were implemented by JSC "Shakhta Yuzhnaya", "Kiselevsky Razrez" Ltd., the coal mining enterprises of the Kemerovo region.
\end{abstract}

\section{Introduction}

Ensuring industrial safety and labour protection of coal mining enterprises employees is one of the most difficult social-economic and moral challenges of Kuzbass coal industry.

The number of accidents and the rates of fatal injuries in Kuzbass are significantly higher than at European coal mining enterprises with comparable volumes of coal mining $[1,2]$. At the same time there are practically no technical and technological reasons that could lead to major accidents and emergency events at Kuzbass mines.

The basic factors of emergency events and accidents with severe consequences are the following: violation of technology; non-compliance with mandatory safety requirements when performing technological operations; commission of faulty, dangerous, forbidden actions by employees of all levels - workers, foremen, mine overseers, first-line managers, middle and top managers. Industrial safety requirements are violated by both contractors as well as technical and engineering employees [3].

Thus, the current level of fatal, severe, minor injuries is a consequence of the so-called "human factor". Personal reasons such as faulty, careless or dangerous methods of work, deviation from job descriptions and technological instructions, non-compliance with special safety measures, violation of labour discipline, aspiration to overfulfillment of the production plan at the expense of evasion from safe production rules are the causes of 93$97 \%$ of industrial injuries of different types (including fatal cases) in comparison to $3-7 \%$

*Corresponding author: kennedy22.1963@yandex.ru 
caused by dangerous working conditions (mining-and-geological, natural and technicaland-technological factors).

\section{Materials and methods}

The methodological basis for the effective functioning of a complex occupational, industrial and environmental safety management system is domestic and international standards: GOST R 12.0.006-2002 "Occupational safety standards system. General requirements on occupational health and safety management in organisation system", the international standard OHSAS 18000 "Occupational Health and Safety Management System", the project National standard "General requirements on occupational safety and industrial safety management system", where occupational, industrial and environmental safety management system is presented as a course of actions, regulated in the form of local documents: job descriptions, occupational safety instructions, etc. The key conditions for the effective functioning of the system are competence and professional literacy of staff, interaction and partnership of enterprise management with public organisations, state bodies of supervision and control, municipal labour authorities.

Nowadays, the modern occupational and industrial safety management system at coal mining enterprises of Kuzbass represents a relatively wide range of measures aimed at preserving the life and health of mine workers, preventing accidents and their consequences. Traditional methods of organising work on labour protection correspond to the current level of management and development of production, though, they are not effective enough. The disadvantages of the existing safety management systems at mines include: the system is redundantly formalized, the staff is not sufficiently interested in meeting the safety requirements, in some cases employees want to overfulfill the targets by violating safe production regulations, there is a weak feedback from employees on safety issues, as well as the invalidity of motivational appeal for the staff to meet safety requirements.

\section{Results and discussion}

The problem of production safety increase at coal mines can be solved not only by expanding technical, technological and organisational measures, but also by exploiting the "human factor". If the so-called "human factor" is universally recognized as the main cause of production injuries, why not to use it to deal with the problem mentioned. There is a critical need to find some new measures meeting modern conditions and requirements that would allow further reduction of injuries and accidents at Kuzbass coal mining enterprises.

Along with the traditional methods of organising occupational safe and health activities, it is legitimate to introduce new approaches and directions that would correspond to the current level of industrial safety management and production development. Active involvement of personnel in safety management process by forming internal motivation for unconditional compliance with labor protection requirements, as well as appropriate behavior in hazardous industrial situations is one of the most progressive approaches that can be implemented in two directions:

- the increase in the level of communicative and psychological competence of managers and specialists in the direction of teaching methods of information and psychological impact on group and individual professional consciousness of the enterprise staff;

- the combination of material incentives and disincentives for compliance with safety requirements. 
The main psychological regulators of safe professional behavior of employees are not only individualized personal characteristics that were formed during ontogenetic development (caution, risk tolerance, impulsiveness, discipline, courage, self-confidence, inattention, etc.), but also coordinated motives and attitudes (willingness to violate or readiness to comply with), group and individual perception of norms, rules, stereotypes of professional activity ("as it should be", "as it is correct", "like everyone does", "as it has always been done") including those related to health and safety rules applied while conducting mining operations and other technological processes; the need and accuracy of their observance, possibilities of evasion, etc., which were developed in a definite labour collective.

The degree of maturity of motives, attitudes, concepts provides and allows predicting the direction of professional behavior with a high degree of probability, including those aspects that are related to risk tolerance and meeting safety requirements [4].

The considered course of action suggests educating managers and labour protection specialists on alternative methods of providing subordinates with information on safety, which include specific speech strategies designed to increase the effectiveness of psychological impact on subordinates. It will allow building intrinsic motivation and determination of staff to comply with labour protection requirements in the course of the communication process regardless of the management hierarchy level. Exerting pressure in the right area and employing labour behavior management that reduces labour riskogenics is only possible, if employees themselves are aware of the need to comply with safety regulations, use safe techniques for work performance, and are willing to act accordingly $[5]$.

Methods of psychological impact on personnel, including manipulative ones, are the most important methods of personnel management, which dynamically combine all the necessary and legal techniques and ways of influence (suggestion, infection, pressure, persuasion, placebo, purposeful dissemination of rumors; prohibition, hints, compliments, requests, etc.), induce or restrain employees, form certain moods and opinions at the workplace.

By using arguments, manipulating information, and applying persuasion all leaders and specialists involved in labour protection management as well as industrial and environmental safety management at mines in the course of promoting labour protection should strive not only to broadcast information through interpersonal communication, but also to inspire intolerance towards violators of safety requirements, motivate unconditional compliance with such requirements as well as reinforce positive stereotypes of safe and professional behavior at a particular workplace.

Employees tend to simplify their operations while performing work, as a consequence they fail to take certain factors into account, lose attention, show carelessness, excessive self-confidence, and risk taking. Change in habitual behavior, not only of an individual employee, but also of most workers, is merely possible if external information becomes "internal property", an element of personal experience, a persistent inner conviction.

Supplying employees with information on safety issues does not have to be limited by "passive forms" such as instructing, lecturing, providing reference books, inviting to thematic exhibitions.

Using manipulative tactics and techniques presents wide possibilities and can be applied at various levels, but the effectiveness of its impact largely depends on communicative competence (communicative qualities, communicative skills, applying different approaches to employees). In particular, the works of A. Cudworth and Mohammad Abu-qulah justify the use of the following manipulative techniques that can enhance the leader's persuasion of employees: 
- the "Cards Juggling" technique is selecting and demonstrating factual nuances of an event or erroneous or dangerous actions that led to an injury or accident, at the same time ignoring or concealing some details of the event in order to impose a certain attitude towards the person or event;

- the "Simplification" technique is based on the fact that along with a number of general truths, an observation/assertion, that does not correspond to reality and is perceived by subordinates with no criticism, is proclaimed;

- the "Label Sticking" technique is identifying an event (which resulted in an industrial accident, emergency or prevented injury, accident) or an employee (who violated safety rules once/has constantly violated safety rules) by a word or expression that originally contains an acute negative tone in subordinates' minds;

- the "Pretending to be One of the Team" technique is a method of winning employees, shortening the distance between a manager and his subordinates by identifying with them through declaring "I am the same as YOU are", "I am one of YOU", "I feel the same as YOU do";

- the "Witness" technique is a reference to a positive or negative evaluation of an employee's idea, action or professional behavior, presented by a reputable or a highly competent person, for example, a reference to the opinion of the well-respected CEO of a coal mining enterprise in the course of introducing a new polymer resin based roof strengthening technology;

- the "Insinuation" technique is based on objectively existing differences that subordinates are aware of;

- the "Follow Everyone" technique is expressed in the manager's or the labour protection specialist's persuading the team that the overwhelming majority of the workers on the site (the mine as a whole) share a certain opinion, consequently, others have no alternative, but to join this opinion and behave correspondently;

- the "Axiom" technique means supplying safety requirements information in the form of indisputable truth, for example: "Employees of our coal mining enterprise must comply with all safety requirements unquestionably and unconditionally";

- the "Aggressive Sale" technique is attributing or subjectively accentuating causes of emergency/traumatic situations, accidents as a preventive measure;

- the "Transferring" technique is a projection of an approving attitude from something well-known to something new and incomprehensible; the technique is especially effective when innovations are to be introduced in safety regulations, since it is intended for workers' noncritical perception. The main difficulty is to find a suitable image or an example [6-9].

According to Pink D.H., in order to improve the efficiency of labour protection and industrial safety in the course of instructing employees it is legitimate to use information that causes fear and is supported by statistical (or "pseudo-statistical") data. Frightening information is distributed for the purpose of changing workers' attitude towards risks associated with hazardous industrial situations (for example, for encouraging people's active use of personal protective facilities as an effective way of preventing dangers) [10].

If the communicator's implicit purpose is to "intimidate" employees, it is advisable to adhere to the following recommendations when transmitting information:

- the message should express concern about possible consequences of erroneous, risky or careless actions of employees;

- at the same time the message should contain an obvious positive evaluation of the recommended "correct" actions and measures;

- the message should contain both logical argumentation and value judgments based on common sense and the logic of the common mind (undeniable truths);

- the actions recommended should be specific, detailed and elabourated, as well as be perceived as effective means of preventing potential danger; 
- the message should correspond with the level of awareness and competence of the employees who perceive information;

- the information should contain specific examples in which the employee who systematically violates labour protection requirements inevitably experiences more losses than acquisitions including financial ones, and vice versa, strict compliance with labour protection requirements makes the employee more successful in the production process;

- the communicator's level of authority is essential (the higher the level, the less critical the perception of the recipients).

According to Drupsteen L., Groeneweg J., the formation of a company's safety culture begins not only with imposing high responsibility for accidents on the company management, but also with the ability of the management to communicate with the personnel, make it a personal concern for everyone and convince every employee that compliance with all safety requirements and regulations is necessary and mandatory. This is "human factor" management, which makes it possible to achieve impressive results [11]. Communicative and psychological competence of the personnel: master, mine overseer, engineer, operations manager, headmaster and other specialists (not only in the field of expertise and Process Safety Management) can influence the level of traumatism at coal mining enterprises. Highly developed intrinsic motivation, determination to comply with safety regulations and self-control act as significantly more powerful regulators of workplace behavior, which can exclude violations of occupational safety requirements more effectively then administrative pressure and operating control [12].

The analysis of foreign practice shows that one of the directions of improving the quality of HSE Management System of coal producers is a combination of financial incentives and disincentives for the personnel to meet the requirements of individual and collective safe conduct [13].

In particular, M. Evans states that the amount of incentive payments should correspond to or outstrip the period of accident-free work, and economic sanctions should be perceived by employees as justified and fair measures increasing pressure in the area demanded [14].

Being one of the most effective methods of influencing employees labour behavior and motivation, financial encouragement of the personnel is aimed at eliminating the factors which contribute to violating labour protection rules and neglecting personal safety, as well as increasing the interest of the staff in ensuring safe labour conditions at the workplace in particular and at the enterprise as a whole). The standard of financial incentives for mine employees' complying with the requirements of individual and collective safe conduct includes a system of economic measures (sanctions and incentives) [15].

The leading form of encouragement is bonus, which is extremely effective, being gradual, meaningful and corresponding to the principles of "graduality" and "tangibility". Thus, payments for compliance with / not violating security requirements should not be regular, otherwise it may cause habituation and relaxation of vigilance (the employee is clearly aware of the linear relationship between specific professional actions and the financial encouragement); a large one-time bonus contributes to the formation of increased remuneration expectations of the staff. Bonuses should comprise at least $15-20 \%$ of the average month, quarter or other reporting period's earnings. Publicity is also a way of intensifying the effect of financial rewards [16].

\section{Conclusion}

The analysis of the efficiency of the occupational safety management system applied in the coal mining industry of Kusbass shows that the solution to this problem is impossible without active involvement of the coal mining industry personnel in the process of ensuring safe mining operations. It is necessary to emphasize that the direction considered in the 
article reflects some principles of the "Zero Accident Vision" concept, applied to corporate programs of the metallurgic and mining companies in the European Union countries, Finland and the Netherlands in particular [17]. It is recommended in order to form psychological attitudes to meeting safety requirements. In combination with financial incentives, these actions will provide effective management of the personnel's motivation. The proposed methods were tested and received approval at the coal mining enterprises of the Kemerovo region, OAO "Shakhta Yuzhnaya", OOO "Kiselevsky Razrez".

\section{References}

1. J.L. Hawksley, Haz. Mat., 65 (2), 109-121 (1999)

2. M. Cehlár, J. Janočko, Z. Šimková, T. Pavlik, E3S Web of Conf., 15, 01019 (2017)

3. M. Prekopová, J. Janočko, Geol. Carp., 60:6, 485-494 (2009)

4. G. Wittenberger, M. Cehlár, Z. Jurkasová, Acta Montanistica Slovaca, 17:4, 241-246 (2012)

5. J. Song, Y. Zhu, F. Dong, Cross Strait Quad-Regional Radio Science and Wireless Technology Conference 24, 01124 (2011)

6. A. Cudworth, Strat. Com. Man., 14 (1) 16-19 (2009)

7. Mohammad Abu-qulah, Int. J. Man. Fin. Educ, 24 (6) 42-55 (2014)

8. W. Wen-Qing W, Z. Lei, Z. Wei-hua, Proc. Engin.,4, 24-52 (2013)

9. F. Mingchao, S. Bin, Sec. Int. Conf. Dig. Manuf. Autom, 25, 03124 (2011)

10. D.H. Pink, Drive: The Surprising Truth about What Motivates Us (Canongate Books Ltd., Great Britain, 2010)

11. L. Drupsteen, J. Groeneweg, G. Zwetsloot G., J. Occup. Saf. Erg., 19 (1) 63-77 (2013)

12. G. Chistyakova, E. Bondareva, K. Demidenko, E. Podgornaya, O. Kadnikova, E3S Web of Conferences, 15, 04010 (2017)

13. G. Pinigina, I. Kondrina, S. Smagina, E3S Web of Conferences, 15, 04017 (2017)

14. M. Evans, J. Manag., 12 (2), 203-222 (2006)

15. Zwetsloot, M . Aaltonen, J. Wybo, J. Saari, P. Kines, R. Op De Beeck, Saf. Sci., 58(3), 41-48 (2013)

16. K. J. Foster, Risk Anal. 17 (2), 215-225 (1997)

17. K.M. Dange, R.T. Patil, Int. J. Engin. Sci. Inven., 2(7), 14-19 (2013) 